\title{
Continuous Monitoring of Steel Corrosion Condition in Concrete Under Drying/Wetting Exposure to Chloride Solution by Embedded $\mathrm{MnO}_{2}$ Sensor
}

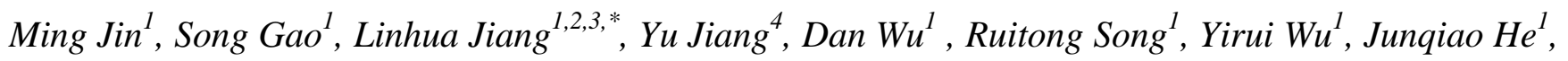 \\ ${ }^{1}$ College of Mechanics and Materials, Hohai University, Nanjing 210098, PR China \\ ${ }^{2}$ National Engineering Research Center of Water Resources Efficient Utilization and Engineering \\ Safety, Nanjing 210098, PR China \\ ${ }^{3}$ Engineering Research Center on New Materials and Protection in Hydraulic, Jiangsu Province, 1 \\ Xikang Rd., Nanjing 210098, PR China \\ ${ }^{4}$ Department of Civil \& Environmental Engineering, Washington State University, Pullman, WA \\ 99164, USA \\ *E-mail: hhulhjiang@gmail.com, jinming@hhu.edu.cn
}

doi: $10.20964 / 2017.12 .77$

Received: 7 July 2017 / Accepted: 14 August 2017 / Published: 12 November 2017

Corrosion condition of steel in concrete under drying/wetting exposure to chloride ion solution was monitored based on various electrochemical techniques including linear polarization (LP), electrochemical impedance spectra (EIS) and half-cell potential (HCP) through embedded $\mathrm{MnO}_{2}$ reference electrode. In LP measurement, polarization resistance of steel was equal to the slope of curves. However, in EIS measurement, polarization resistance of steel was calculated by adding the resistance of protective film to the charge transfer resistance derived from EIS data by means of the equilibrium circuit model. Corrosion state of steel was differentiated based on the obtained corrosion current density calculated by the polarization resistance according to the Stern-Geary equation by introducing the "divergent region". Furthermore, potential of steel with respect to embedded $\mathrm{MnO}_{2}$ reference electrode was higher than $-0.400 \mathrm{~V},-0.400$ to $-0.516 \mathrm{~V},-0.516$ to $-0.710 \mathrm{~V}$ and lower than $0.710 \mathrm{~V}$ for passive state, critical corrosion state, moderate corrosion rate state and high corrosion rate state respectively. Continuous non-destructive monitoring corrosion condition of steel in concrete was achieved through embedded $\mathrm{MnO}_{2}$ reference electrode via electrochemical techniques.

Keywords: $\mathrm{MnO}_{2}$, Reinforced Corrosion, Monitoring, Concrete, EIS, LP, HCP, Sensor

$\underline{\text { FULL TEXT }}$ 
(C) 2017 The Authors. Published by ESG (www.electrochemsci.org). This article is an open access article distributed under the terms and conditions of the Creative Commons Attribution license (http://creativecommons.org/licenses/by/4.0/). 